\title{
Microbial Synthesis of Sliver Nanoparticles by Penicillium digitatum FCMR-728 and their Bionanocatalytic Reduction of 4-Nitrophenol and Antibacterial Activity
}

\author{
A.N.Z. Alshehri* \\ Department of Biology, University College in Al-Jummum, Umm Al-Qura University, \\ Makkah, 21955, Saudi Arabia \\ *Corresponding author
}

\section{Keywords}

Penicillium digitatum, Silver nanoparticles,

Biosynthesis, bionanocatalyst,

Reduction, 4-

Nitrophenol,

Antibacterial activity

\section{Article Info}

Accepted:

14 December 2018

Available Online:

10 January 2019

\section{A B S T R A C T}

The development of a protocol for biosynthesizing nanomaterial in an eco-friendly manner is a major concern in the field of microbial nanotechnology. In this study, microbial synthesis of silver nanoparticles (AgNPs) with a high level of bionanocatalytic activity was accomplished utilizing cell extracts of Penicillium digitatum FCMR-728 as the agents for reducing, capping and stabilizing. The presence of AgNPs was confirmed by an indication of a surface plasm on resonance band via UV-vis spectrum at $550 \mathrm{~nm}$. Evidence of fairly uniformly spherical AgNPs being synthesized was shown by transmission electron microscopy images. The sizes of the nanoparticles increased with reaction time by an average of $5 \mathrm{~nm}$ to $30 \mathrm{~nm}$. The formation of nanocrystalline silver particles was verified by X-ray diffraction analysis. The presence of functional groups on the surface of biosynthesized $\mathrm{AgNPs}$, such as $\mathrm{C}=\mathrm{O}, \mathrm{O}-\mathrm{H}, \mathrm{N}-\mathrm{H}, \mathrm{C}-\mathrm{O}-\mathrm{C} \mathrm{C}-\mathrm{H}$ and $\mathrm{C}-\mathrm{OH}$, which play role in the AgNPs stability, was shown by Fourier transform infrared spectra. Biogenic AgNPs were utilized as bionanocatalysts for nanoreduction of 4-nitrophenol compound, where the linear correlation with AgNPs concentration of the reaction rate constant led to the rate increasing from $0.61 / \mathrm{min}$ to $1.63 / \mathrm{min}$, via the AgNPs amounts increasing from $1.53 \times 10^{-6}$ to $17.58 \times 10^{-6} \mathrm{mM}$. The synthesized AgNPs also showed a very high degree $\left(4.04 \times 10^{5} / \mathrm{min} / \mathrm{M}\right)$ of normalized bionanocatalytic activity. This was significantly higher than the same activity for AgNPs that were synthesized by other traditional of chemical and biological methods. Moreover, the high toxicity of biosynthesized AgNPs against human pathogenic bacteria raises the potential for efficiently applying AgNPs as antibacterial agents.

\section{Introduction}

The compound of 4-Nitrophenol (4-NiP) is a highly toxic and refractory pollutant, and It is obtained from various industrial processes of pigments, agrochemicals and pharmaceuticals (1). A less poisonous alternative is 4- aminophenol (4-AmP), which has applications in photography, as a drying agent and corrosion inhibitor, and in the manufacture of antipyretic drugs and analgesic $(2,3)$. The reduction of $4-\mathrm{NiP}$ to $4-$ AmP therefore has great importance for the purpose of abating pollution and the 
regeneration of resources. Any efficient way of catalyzing this reduction of 4-NiP to 4AmP has been found to be by applying metal nanoparticles using $\mathrm{NaBH}_{4}$ (2). Among the metal nanoparticles that have been investigated for this purpose are gold nanoparticles (AuNPs) (4), palladium nanoparticles (5), silver nanoparticles (AgNPs) (6), platinum nanoparticles (7), copper nanoparticles (8), nickel nanoparticles (9) and iron nanoparticles (10). In comparison, AgNPs (silver nanoparticles) have high catalytic activities under moderate circumstances (2). As well as in comparison to AuNPs, rare studies have investigated AgNPs as bionanocatalytic reduction. In a study for instance the AuNPs synthesized by PVP solution exhibited a high level of catalytic activity for 4-NiP reduction by $3.72 \times 10^{-3} / \mathrm{s}$ as the reaction rate constant $\left(K_{a p p}\right)(3)$. Composite of polyaniline nanofiber and gold nanoparticle is an efficient catalyst for activating the 4-NiP reduction by $11.7 \times 10^{-3} / \mathrm{s} K_{a p p}$ (11). Furthermore, biogenic AuNPs synthesized by Cylindrocladium floridanum, Rhizopus oryzae and Breyniarham noides exhibit evidence of good catalytic activities for reduction of $4-\mathrm{NiP}$ by $4.45 \times 10^{-4} / \mathrm{s}, \quad 4.33 \times 10^{-3} / \mathrm{s}$ and $9.19 \times 10^{-3} / \mathrm{s}$ $K_{a p p}, \quad$ respectively (12-14). Many conventional physical and chemical approaches have been utilized for synthesizing AgNPs, but there are concerns over the high energy input required in physical approaches and the generation of hazardous organic reagents in chemical processes, which impact negatively on the environment in general $(14,15)$. This requires green methods to be developed via ecofriendly and affordable approaches. Of these methods for the synthesis of AgNPs, microbial resource is found to be both affordable and eco-friendly approaches. The biosynthesis of AgNPs using microbes resource, such as bacteria, fungi and actinomycetes have been used and reported previous successfully (16-19), but there are variations in the AgNPs features, when they are synthesized by various kinds of microorganisms. Moreover, the microbes used for the biosynthesis of AgNPs are limited, which necessitates identifying more effective microbial resource. Due to their excellent efficacy in bioaccumulation of metals and in secreting large quantities of proteins, fungi may offer a better solution in the production of AgNPs on an industrial scale (20), furthermore the cell extracts of fungi can also function as agents in capping, reducing and stabilizing for the synthesis and stabilization of nanoparticles without the need to add any more agents. AgNPs biosynthesis is preferable using cell extracts due to its simplicity and there being no need for further processing (21-24). For instance, biosynthesis has been achieved of a mixture comprising of rod-shaped, triangular, spherical and hexagonal AuNPs using cell extracts of Trichoderma viride (22), and spherical AuNPs with irregular have been synthesized using cell extracts of Rhizopus oryzae (13). However, the use of cell extracts of the fungus Penicillium digitatum in the synthesis of AgNPs has either rarely or not been reported previously despite its recognition as a microbial resource for the synthesis of metal nanoparticles that is both eco-friendly and economically important (25, 26). Furthermore, catalytic activities of AgNPs biosynthesized by microorganisms resources are notably lower compared to those of chemical AgNPs. This makes it highly important to develop biosynthesis processes for obtaining AgNPs efficiently with a high level of catalytic performances. In this study, biosynthesis of high nanocatalytic activity represented in AgNPs were achieved by cell extracts of $P$. digitatum FCMR-728 as the agents for capping, reducing and stabilizing. With respect to the physicochemical properties of the biosynthesized AgNPs were defined using transmission electron 
microscopy (TEM), UV-vis spectroscopy, Fourier transform infrared spectroscopy (FTIR) and Xray diffraction (XRD). Additionally, the catalytic performances of the biosynthesized AgNPs for reducing of 4$\mathrm{NiP}$ using $\mathrm{NaBH}_{4}$, as well as, the antibacterial activity of biosynthesized AgNPs were examined.

\section{Materials and Methods}

\section{Biosynthesis of AgNPs}

Cell extracts for the biosynthesis of AgNPs were prepared by first growing the fungus $P$. digitatum FCMR-728 (was kindly provided by King Fahd Center for Medical Research Jeddah-Saudi Arabia) in a modified medium of martin broth (Sigma-Aldrich, USA), at $\mathrm{pH}$ 7, consisting of $(\mathrm{g} / \mathrm{L}) 1.0\left(\mathrm{NH}_{4}\right)_{2} \mathrm{SO}_{4}, 1.0$ $\mathrm{KH} 2 \mathrm{PO} 4,0.5 \mathrm{MgSO}_{4} \cdot 7 \mathrm{H}_{2} \mathrm{O}$, and 2.0 glucose. This was incubated for 4 days at $30^{\circ} \mathrm{C}$ aerobically before harvesting using a sieve and qualitative filter paper. Subsequently, the Mycelium of $P$. digitatum FCMR-728 was rinsed using sterile deionized water to remove traces of medium components. This rinsing process was repeated two more times before being re-suspended in a buffer solution of phosphate sodium (50 $\mathrm{mM}$ at $\mathrm{pH} 7$ ), and lysed for 40 minutes by ultrasonication using an ultrasonic processor (CPX 750, USA). Following centrifugation process for 20 minutes at $10,000 \times g$ and a temperature of $4^{\circ} \mathrm{C}$, filtration of the supernatant was done using a $0.45 \mu \mathrm{m}$ syringe of Millipore filters to use them as cell extracts. Protein concentration in the cell extracts was adjusted by Bradford assays to $100 \mathrm{mg} / \mathrm{L}$, and $1 \mathrm{mM}$ of $\mathrm{AgNO}_{3}$ solution was added to the cell extracts to synthesize AgNPs. The mixture of the reaction was then incubated for 9 days at $30^{\circ} \mathrm{C}$ in the dark. An experiment without the use of cell extracts was conducted as a control.

\section{AgNPs characterization}

Samples of prepared AgNPs were intervally collected for monitoring their characteristics at different time using a UV-vis spectrophotometer (Metash UV-9000, China) and a TEM (Tecnai G2 Spirit FEI, The Netherlands). An Inductively Coupled Plasma Optical Emission Spectrometer (ICPOES, Perkin-Elmer Optima 2000 DV, USA) was utilized to determine the concentration of AgNPs, and an XRD with a D/max-2400 diffractometer (Rigaku, Japan) to analyze their crystallinity. A Shimadzu IRPrestige-21 FTIR Spectrophotometer (Japan) was then used at wavelength between 750 and $3750 / \mathrm{cm}$ to examine the surface of the nanoparticles for conjugation of proteins.

\section{Bionanocatalytic activity of AgNPs for 4- NiP reduction}

The procedure is detailed which was adopted for the catalytic activity of biogenic AgNPs for reduction of 4-NiP. A mixture was made of $0.1 \mathrm{~mL}$ of $4-\mathrm{NiP}(2 \mathrm{mM})$ and $0.4 \mathrm{~mL}$ of $\mathrm{NaBH}_{4} \quad(30 \mathrm{mM})$ and various volumes $(0.0025,0.005,0.01,0.02,0.03 \mathrm{~mL})$ of biogenic AgNPs $(114.72 \mathrm{mg} / \mathrm{L})$ in a standard quartz cuvette $(3 \mathrm{~mL})$ with the final reaction volume regulated to $2 \mathrm{~mL}$ using sterile water. A control experiment based on cell extracts was carried out under identical conditions. $\mathrm{UV}$-vis spectra of the samples were noted to monitor 4-NiP reduction in the range $250-500$ $\mathrm{nm}$. The absorbance decrease was measured to evaluate the apparent rate constants $\left(K_{a p p}\right)$ of catalytic reaction at $400 \mathrm{~nm}$.

\section{Antibacterial activity of AgNPs}

The influence of AgNPs as antibacterial agent against human bacterial pathogens was examined by the method of standard disk diffusion. The Gram positive (Bacillus subtilis, MLAMC 853, Staphylococcus 
aureus, MLAMC 638) and Gram negative (Escherichia coli, MLAMC 925 and Serratia marcescens, MLAMC 276) bacterial pathogens were obtained from Microbiology Laboratory, King Abdul-Aziz Medical City Makkah - Saudi Arabia. Colonies of the tested bacteria were freshly used in the experiments, and $100 \mathrm{ml}$ of inoculum was spread onto Mueller-Hinton agar plates agar plates. The inocula of each species were prepared by growing a single colony of each the species on Mueller-Hinton liquid medium overnight at $37^{\circ} \mathrm{C}$ on a rotary shaker, subsequently the cultures were diluted using $0.9 \% \mathrm{NaCl}$ to $0.5 \%$ of Mcfarland standard before application on the plates. Various concentrations $(5,10,15,20$, and $25 \mu \mathrm{g} / \mathrm{ml})$ of AgNPs were then loaded on $6 \mathrm{~mm}$ disks. After period of incubation at $37^{\circ} \mathrm{C}$ for $24 \mathrm{~h}$, the inhibition zones were measured. These experiments were conducted in triplicate, and the t-test was used for evaluating significant differences statistically.

\section{Results and Discussion}

\section{Using $P$. digitatum FCMR-728}

Genus Penicillium is recognized like Aspergillus for its ability in secreting various enzymes. These enzymes, including amylases, proteases, urease and protyrosinase, make Penicilliumeco-friendly, and also economically important with respect to the potential for green synthesis of metal nanoparticles such as AgNPs and AuNPs (21). In one of several studies reported for AgNPs synthesis, mycelium of Aspergillus flavus was incubated with silver nitrate solution for synthesizing AgNPs (27). Aspergillus clavatus was used to synthesize hexagonal and spherical AgNPs in the size range $10-25 \mathrm{~nm}$ (28). A demonstration was then made of the synthesis of AgNPs using a green and affordable manner by using cell filtrate of Aspergillus flavus and Aspergillus fumigatus (25,29-31).Comparison with AuNPs, studies of AgNPs synthesis by Penicillium were relatively few and this is first work have reported using $P$. digitatum FCMR-728 for AgNPs synthesis.

\section{Biosynthesis of AgNPs}

The change of color of the reaction mixture confirmed $\mathrm{Ag}^{+}$reduction to AgNPs by using cell extracts of $P$. digitatum FCMR-728. The reaction mixture color turned from pale yellow to dark brown as the biosynthesis proceeded (Fig. 1). AgNPs formation in the reaction solution was observed via recording of the absorption spectra, where after the first day of incubation, the reaction solution exhibited peak of absorption spectra at 550 nm (Fig. 2A), which corresponded to AgNPs surface plasmon resonance (SPR). The strength of this SPR band steadily increased relative to reaction time, which reached a maximum at 7 days (Fig. 2B). The magnitude and morphology of the AgNPs developed at different intervals were examined via TEM analysis (Fig. 3). The synthesized AgNPs were observed to be spherical and almost monodisperse without any assemblage significantly. The size of the formation of AgNPs was noted on the histogram to range from $2 \mathrm{~nm}$ to $7 \mathrm{~nm}$ arising at $12 \mathrm{~h}$, where the average size was $5 \mathrm{~nm}$. The sizes of the AgNPs gradually increased for five days during incubation. On the $5^{\text {th }}$ day, the AgNPs synthesized showed a similar size of distribution of $25-40 \mathrm{~nm}$, where the average was $30 \mathrm{~nm}$. Although the amount of AgNPs synthesized increased, their size stabilized at 5 days. In order to define the stability of synthesized AgNPs, UV-vis spectroscopy was used to monitor the reaction solution. This monitoring was done after one month of storage at a temperature of $20^{\circ} \mathrm{C}$. No changes were evident in the wavelength or strength of the SPR band. This indicates a high level of stability of AgNPs biosynthesis and even 
dispersion in the solution without any assemblages. These the assemblages were prevented due to the strength of the interaction between the AgNPs and proteins surrounding the nanoparticles (13). Relative to the reported microbes, the fungus $P$. digitatum FCMR-728 biosynthesized fairly uniform spherical AgNPs with good stability and dispersity, which are highly desired features of nanoparticles (25).

\section{Characterization of AgNPs}

Figure 4 displays the XRD pattern of AgNPs, which shows four separate peaks at 38.26, 44.28, 64.64 and 77.76. These peaks correspond to the 111, 200, 220 and 311 planes of the face centred cubic structure of the metallic silver (32). As in other studies (12, 33, 34), crystalline AgNPs formed, and the biomolecules in the cell extracts served as factors for stabilizing and capping, which prevented the assemblage of formed AgNPs (14). The biomolecules involved in the synthesis of AgNPs by $P$. digitatum FCMR728 cell extracts were characterized by FTIR spectroscopy. Two major peaks at $3417 / \mathrm{cm}$ and 1648/cm (Fig. 5) were recorded and ascribed to stretching vibration of $\mathrm{O}-\mathrm{H} / \mathrm{N}-\mathrm{H}$ groups and $\mathrm{C}=\mathrm{O}$ groups, respectively $(32,35)$.

The weak band at $2923 / \mathrm{cm}$ corresponded to $\mathrm{C}-\mathrm{H}$ groups (36). The peaks recorded in the finger print region $1200-900 / \mathrm{cm}$, were ascribed to a stretching vibration of $\mathrm{C}-\mathrm{OH}$ and/or C-O C groups (37), and the peak at $883 / \mathrm{cm}$ pointed out the presence of $\mathrm{C}-\mathrm{H}$ groups. These results give support to the idea of protein compounds present on the surface of biosynthesized AgNPs, and the functional groups identified may be utilized in the bioconjugation and immobilization process of different compounds, as these increased the stability of the nanoparticles formed (38).
Nanocatalytic reduction of 4-NiP by biogenic AgNPs

An investigation was conducted of catalytic performance of biogenic AgNPs for reduction of 4-NiP. Due to the red change of the absorption peak of 4-NiP from $317 \mathrm{~nm}$ to 400 $\mathrm{nm}$ in the existence of $\mathrm{NaBH}_{4}$, the modification in the absorption spectra at 400 $\mathrm{nm}$ was monitored in order to track the reaction (14). With the addition of AgNPs, the absorption peak strength at $400 \mathrm{~nm}$ reduced at a fast rate, and a new peak appeared at 300 nm, (Fig. 6A) which suggests the formation of 4-AmP as the reduction product (39). Completion of the reaction within 2-6 minutes was thus shown to be possible with different amounts of AgNPs (Fig. 6B). In the control experiment in which AgNPs were not used, there was a slight decrease in the peak at 400 nm (Fig. 6B), which indicated the catalytic function of nanoparticles. Despite the thermodynamically favorable reduction of 4$\mathrm{NiP}$ to 4-AmP with aqueous $\mathrm{NaBH}_{4}$, the kinetic barrier reduced feasibility due to the large potential difference between the donor and acceptor molecules (14). The AgNPs could assist in the transfer of electrons from $\mathrm{BH}_{4}{ }^{-}$ions to the 4-NiP nitro group, reducing it to 4-AmP, and thereby improving the rate of reaction (12). With the addition of AgNPs in the mixture of reaction, an induction time was noticed before the reduction process, which may due to 4-NiP absorption on surface of the catalyst prior to reaction (13). No induction time was recorded during the current work that could be attributed to the fine dispersity and homogeneous morphology of AgNPs formed, which would lead to a fast adsorption of the reactant on the surface of the catalyst. Given the $\mathrm{NaBH}_{4}$ concentration being higher relative to $4-\mathrm{NiP}$, it is supposed that the catalytic reduction follows pseudo-first-order kinetics. The obvious rate constants $\left(K_{a p p}\right)$ were calculated and the plots of $\ln \left(C / C_{0}\right)$ versus time of reaction process were 
displayed in Figure 7A. The rate constants are shown to vary between $0.61 / \mathrm{min}$ and 1.63/min with AgNPs amount increasing from $1.53 \times 10^{-6}$ to $17.58 \times 10^{-6} \mathrm{mM}$. The reaction rate increased with AgNPs amounts linearly as it clear in Figure 7B. This is likely due to increased reaction site numbers (14). Evaluation of the catalytic performance of AgNPs compared with other nanoparticles produced via chemical and biological methods was made via normalizing the values of $K_{a p p}$ to $K_{\text {nor }}$ by dividing with $\mathrm{Ag}$ concentration (Fig. 7B). The highest values of $K_{n o r}$ of AgNPs were noted to be
$4.04 \times 10^{5} / \mathrm{min} / \mathrm{mM}$. This was comparatively quite higher than values obtained in prior investigations (3, 13, 40-47). For biogenic AgNPs, the $K_{\text {nor }}$ synthesized by Rhizopous oryzae was found to be $16.03 / \mathrm{min} / \mathrm{mM}$. Those AgNPs produced using conventional chemical manner, the $K_{n o r}$ values ranged widely from $0.06 / \mathrm{min} / \mathrm{mM}$ to $1.28 \times 10^{4} / \mathrm{min} / \mathrm{mM}$. Those AgNPs that supported by metal oxide or carbon have a relative high degree of catalytic activity, where the values of $K_{\text {nor }}$ were between $3.75 \times 10^{2} / \mathrm{min} / \mathrm{mM}$ and $3.51 \times 10^{4} /$ $\mathrm{min} / \mathrm{mM}$.

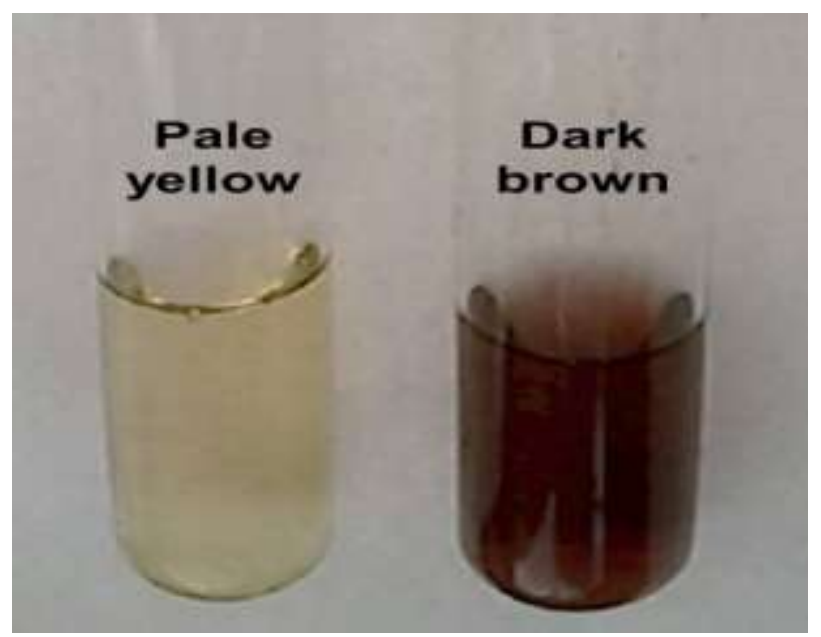

Fig.1 Color change of reduction mixture of $\mathrm{Ag}^{+}$to AgNPs using cell-free supernatants of $P$. digitatum FCMR-728 from pale yellow to dark brown, confirmed the biosynthesis of AgNPs
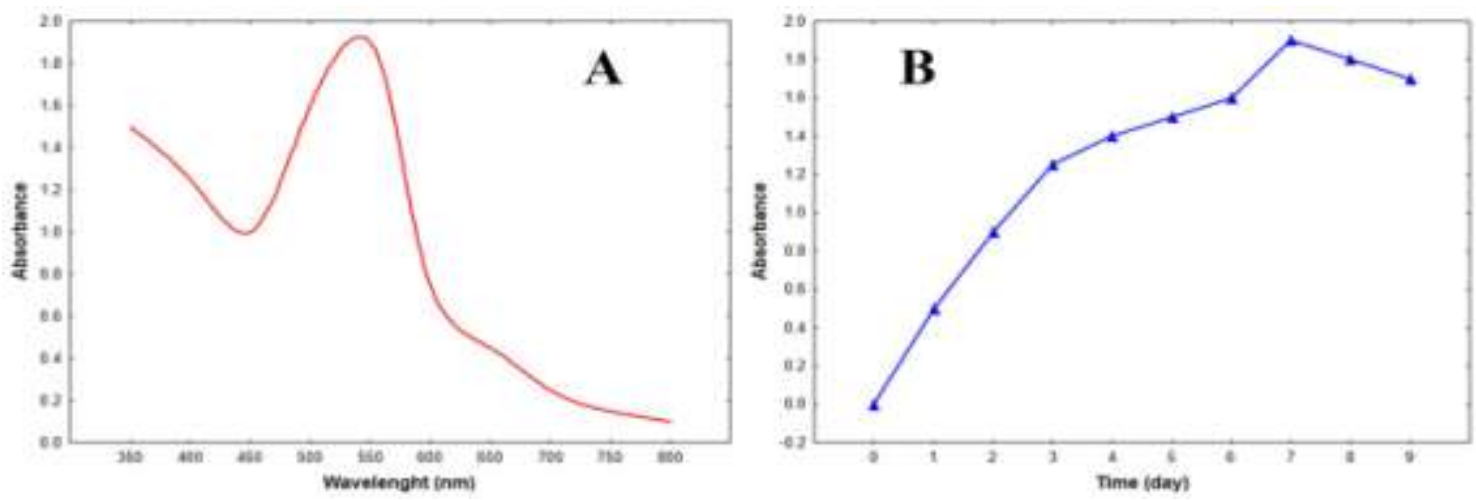

Fig.2 (A) UV-vis spectra of AgNPs synthesized using the cell-free extracts of $P$. digitatum FCMR-728. (B) The intensity change of SPR peak at $550 \mathrm{~nm}$ during the formation of AgNPs. 

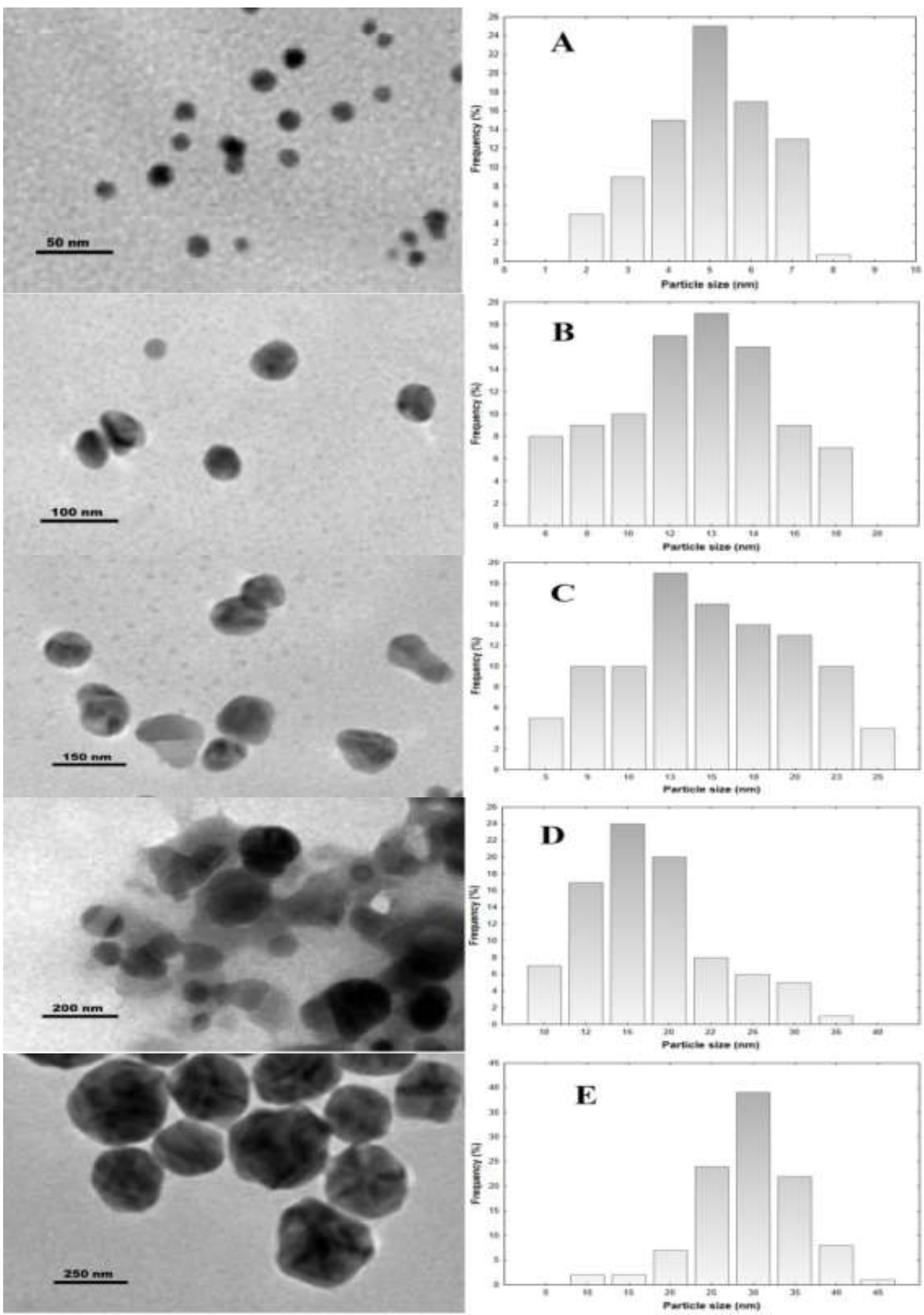

Fig.3 The size and morphology of AgNPs in the synthesizing process. (A) 0.5 day, (B) 1 day, (C) 2 day, (D) 3 day, (E) and 4 day 


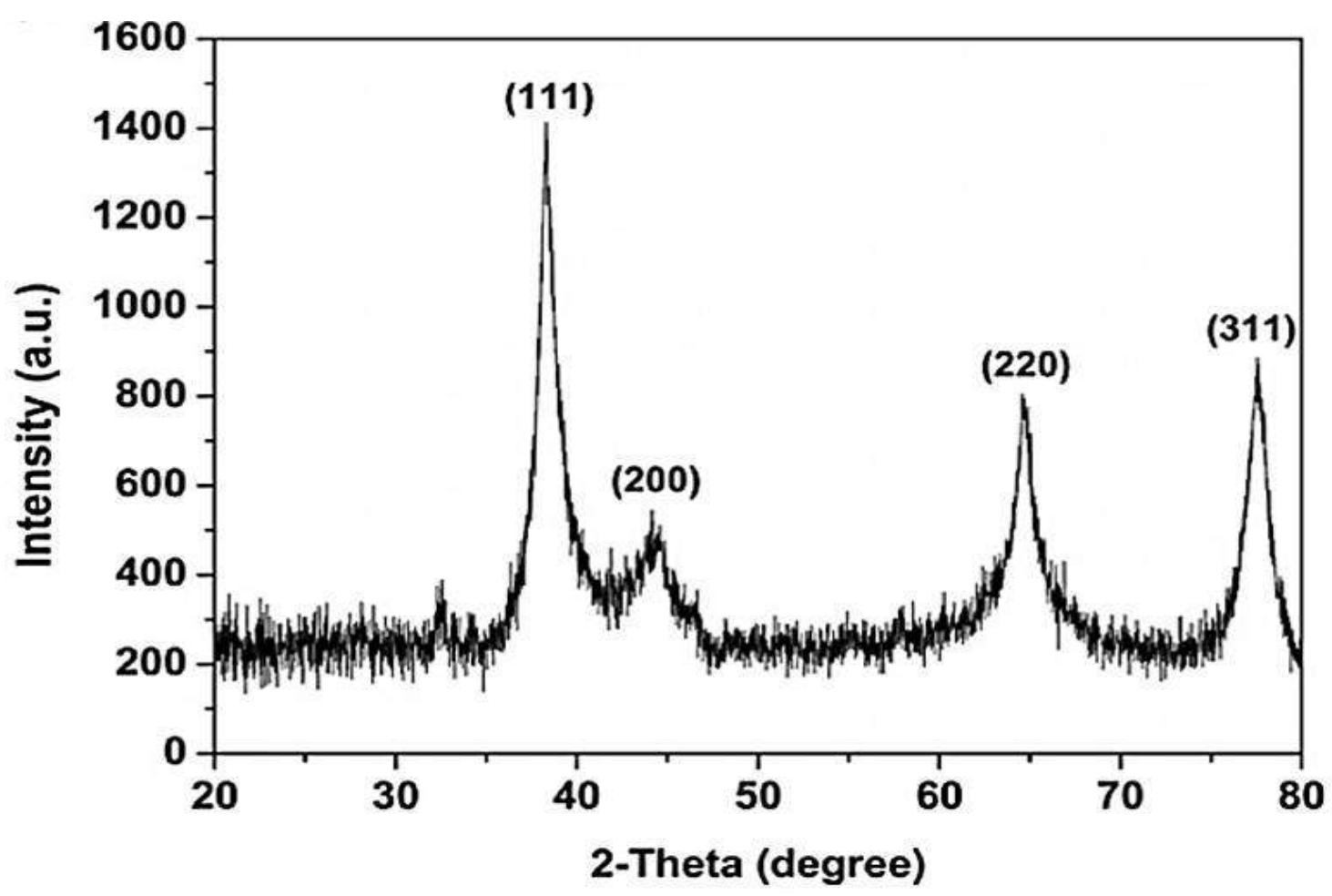

Fig.4 X-ray diffraction pattern of the AgNPs after incubation of cell-free extract of $P$. digitatum FCMR-728 with $1 \mathrm{mM} \mathrm{HAuCl}_{4}$ for 9 days. The principal Bragg reflections were identified

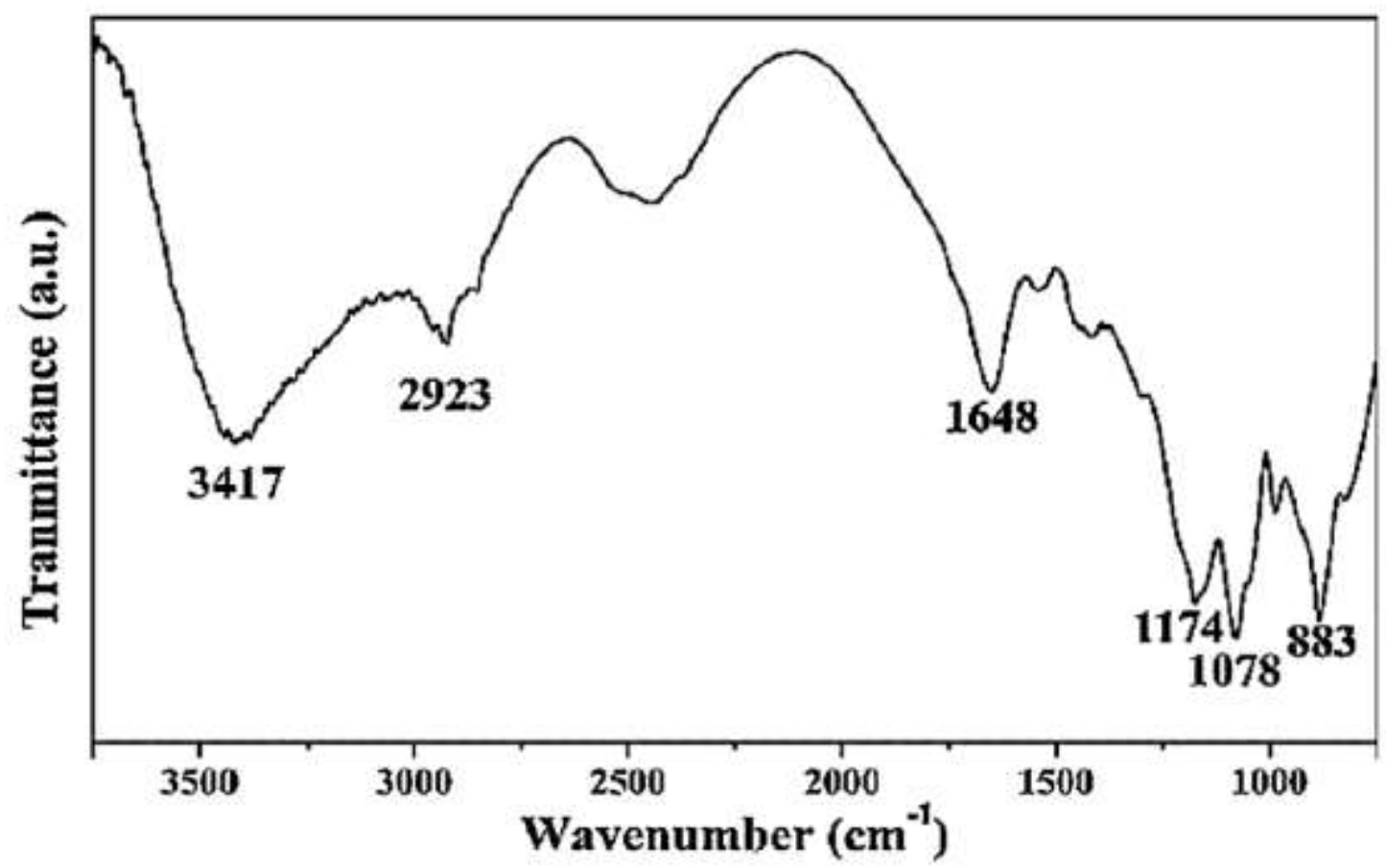

Fig.5 Representative FTIR spectra of AgNPs after incubation of cell-free extract of $P$. digitatum FCMR-728 with $1 \mathrm{mM} \mathrm{HAuCl}_{4}$ for 9 days. 

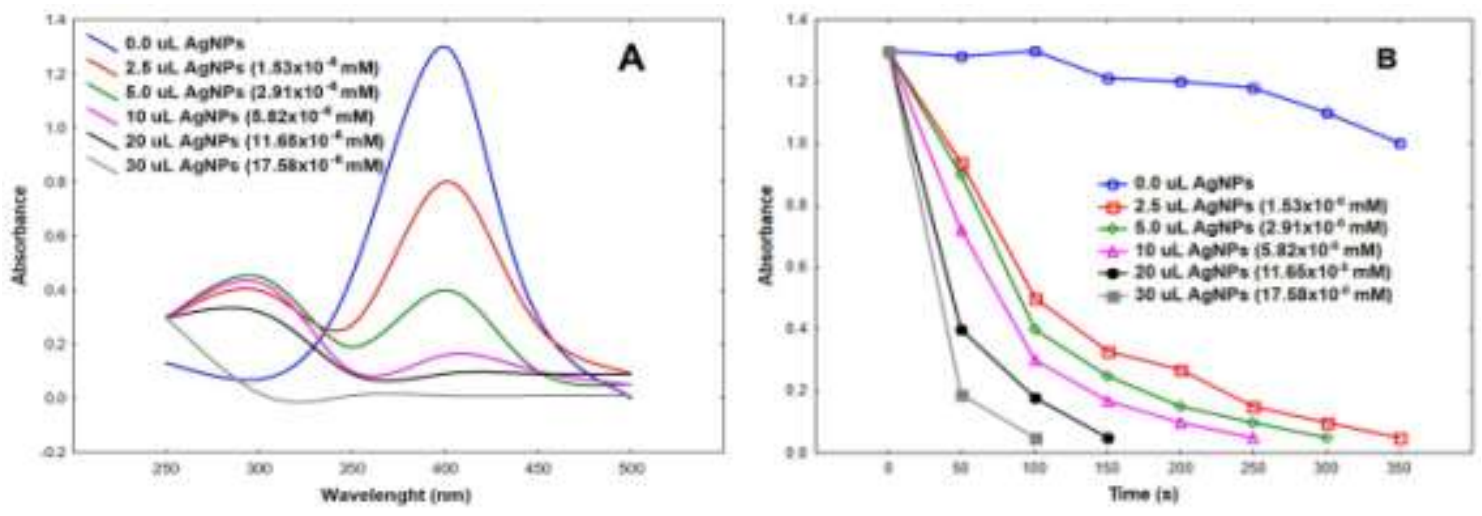

Fig.6 (A) Time-dependent UV-vis absorption spectra for the reduction of 4-NP with addition of different volume of bio-AgNPs. $(2.5 \mu \mathrm{L}, 5.0 \mu \mathrm{L}, 10 \mu \mathrm{L}, 20 \mu \mathrm{L}, 30 \mu \mathrm{L})$. (B) UV-vis absorbance versus time at different concentration of AgNPs
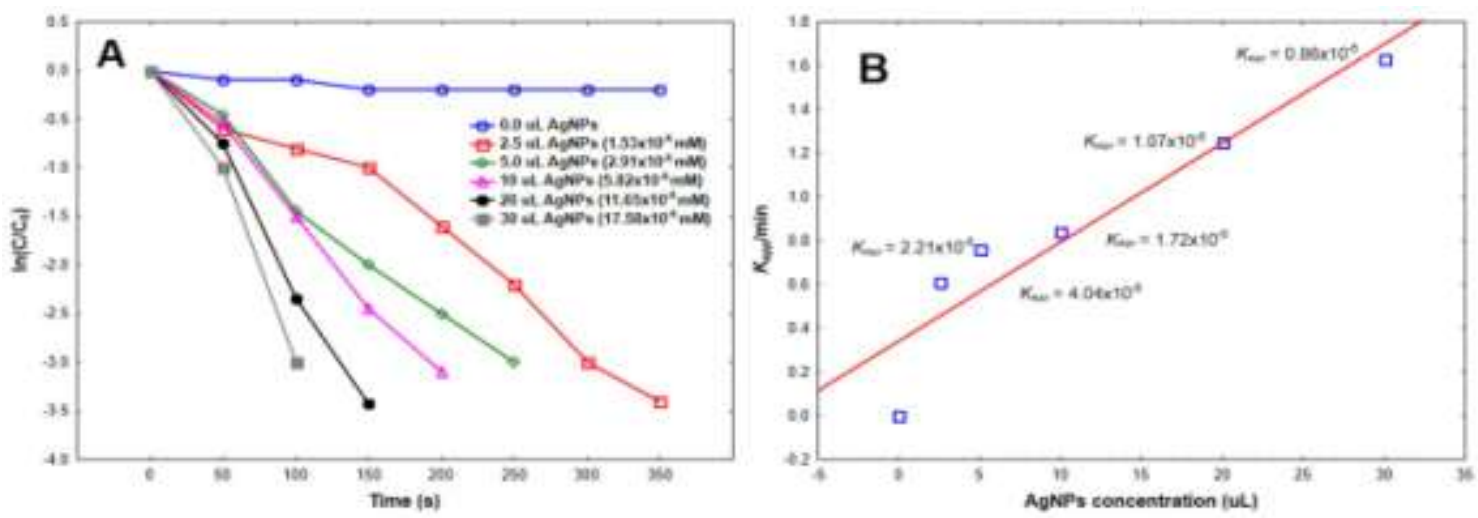

Fig.7 Plots of $(\mathrm{A}) \ln (\mathrm{C} / \mathrm{C} 0)$ against reaction time and $(\mathrm{B})$ reaction rate constant $\left(K_{a p p}\right)$ against amount of AgNPs

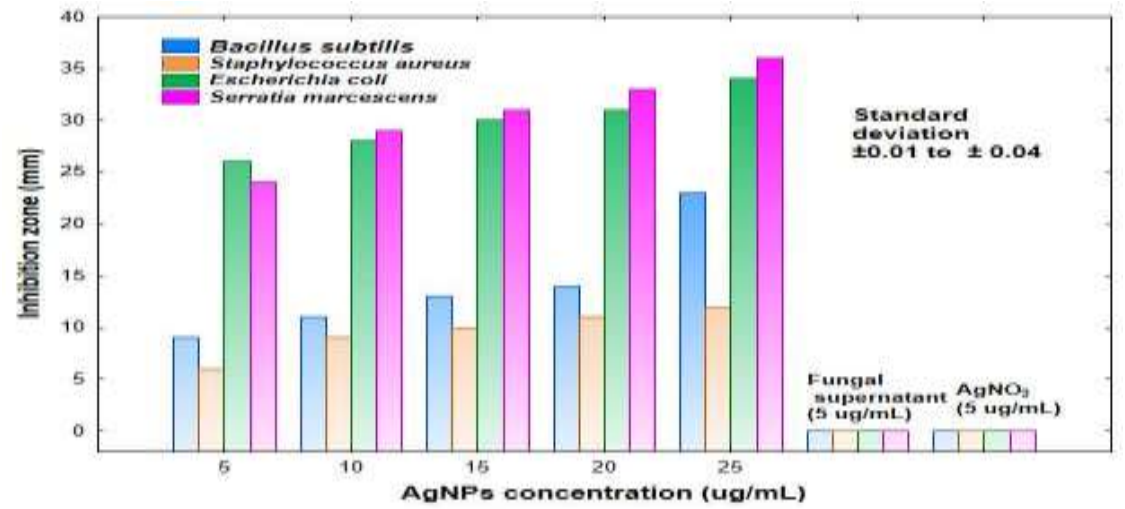

Fig.8 Inhibition zone by different concentrations $\mathrm{AgNPs}$, fungal supernatant and $\mathrm{AgNO}_{3}$ 
These the outcomes indicate that the synthesized AgNPs by cell extracts of $P$. digitatum FCMR-728 exhibited excellent bionanocatalytic activity. This point out a prospect for nanoremediation of environmental pollutants.

\section{Antibacterial effect of AgNPs}

The zone of inhibition method was used to investigate the antibacterial activity of the synthesized AgNPs against the examined human pathogens in this study (Fig. 8). It was recorded that the biogenic AgNPs show a relatively high level of antibacterial activity against Gram-positive and Gram-negative bacteria in comparison to the results of the control experiments $\left(\mathrm{AgNO}_{3}\right.$ and Fungal supernatant). The higher antibacterial activity may be ascribed to AgNP size and greater surface area, as these could have enabled them to reach the nuclear content of the bacteria readily (48). No inhibition zone was recorded for the $\mathrm{AgNO}_{3}$ solution or the extract in the selected bacterial strains. The indication is that the antibacterial potential of $\mathrm{AgNO}_{3}$ and the extract at the concentrations selected did not exhibit any inhibition zone. The restricted efficiency of the $\mathrm{AgNO}_{3}$ as antimicrobial agents is probably due to the irregular release of silver ions that were inadequate concentrations. However, this can be improved by utilizing AgNPs due to their large surface area, which makes them highly reactive $(49,50)$. The AgNPs may be able to adsorb themselves to the surface membrane of the bacterial cell and liberate silver ions that could deactivate the permeability of the cell membranes and replication of the bacterial DNA (51). The big surface area of the nanoparticles also provides them with best connect and opportunity for interaction with the bacterial cells $(52,53)$. The antibacterial activity occurs from the silver cations that were released from those AgNPs involved in modifying structure of the bacteria cell membrane. This results in increased permeability of the bacterial membrane, and thereby ultimately to death of the cells (54).

Increased concentration of biogenic AgNPs was shown to result in an important raise in antibacterial activity. In a study by Kharwar et al., (55), it demonstrated that the antibacterial characteristics of AgNPs, as produced by Aspergillus clavatus, showed an inhibition zone of $10 \mathrm{~mm}$ in the case of $E$. coli. Similar influences on the pathogenic strains of $E$. coli and $S$. aureus have been recorded by Kim et al., (56), and in a separate study Ninganagouda et al., (57) reported that the AgNPs synthesized by A. flavus to have good antibacterial activity against E. coli. However, further research is necessary to examine the antibacterial effects of biogenic AgNPs at the molecular level to widen the scope of their applications.

In conclusions, an eco-friendly process for the synthesis of AgNPs was devised in the present study by utilizing cell extracts of the fungus $P$. digitatum FCMR-728. UV-vis spectroscopy combined with TEM, XRD and FTIR analyses confirmed the presence of uniformly spherical AgNPs with stability and good dispersity. In the presence of $\mathrm{NaBH}_{4}, 4-$ $\mathrm{NiP}$ could be reduced to 4-AmP by using synthesized AgNPs as a highly effective bionanocatalyst. With an increase in AgNPs from $1.53 \times 10^{-6}$ to $17.58 \times 10^{-6} \mathrm{mM}$, the obvious rate constant varied between $0.61 / \mathrm{min}$ and $1.63 / \mathrm{min}$. The highest normalized catalytic parameter $\left(K_{n o r}\right)$ was found to be $4.04 \times 10^{5} / \mathrm{min} / \mathrm{mM}$. The biosynthesized AgNPs exhibited antibacterial activity against the human pathogenic bacteria. It could therefore be used as an ideal potential resource against examined bacteria. Overall, the current work demonstrated a reasonable approach for synthesis of AgNPs eco-friendly with excellent catalytic performances and antibacterial activity. 


\section{References}

1. J.M. Zhang, G.Z. Chen, D. Guay, M. Chaker, D.L. Ma, Highly active PtAu alloy nanoparticle catalysts for the reduction of 4-nitrophenol, Nanoscale 6 (2014) 2125-2130.

2. P.X. Zhao, X.W. Feng, D.S. Huang, G.Y. Yang, D. Astruc, Basic concepts and recent advances in nitrophenol reduction by gold-and other transition metal nanoparticles, Coordin. Chem. Rev. 287 (2015) 114-136.

3. M.Z. Guo, J. He, Y. Li, S. Ma, X.H. Sun, One-step synthesis of hollow porous gold nanoparticles with tunable particle size for the reduction of 4-nitrophenol, J. Hazard. Mater. 310 (2016) 89-97.

4. Y.C. Chang, D.H. Chen, Catalytic reduction of 4-nitrophenol by magnetically recoverable $\mathrm{Au}$ nanocatalyst, J. Hazard. Mater. 165 (2009) 664-669.

5. Q. Wang, W.J. Jia, B.C. Liu, A. Dong, X. Gong, C.Y. Li, P. Jing, Y.J. Li, G.R. Xu, J. Zhang, Hierarchical structure based on $\mathrm{Pd}(\mathrm{Au})$ nanoparticles grafted onto magnetite cores and double layered shells: enhanced activity for catalytic applications, J. Mater. Chem. A 1 (2013) 12732-12741.

6. W. Zhang, F.T. Tan, W. Wang, X.L. Qiu, X.L. Qiao, J.G. Chen, Facile, templatefree synthesis of silver nanodendrites with high catalytic activity for the reduction of p-nitrophenol, J. Hazard. Mater. 217 (2012) 36-42.

7. X.B. Lin, M. Wu, D.Y. Wu, S. Kuga, T. Endo, Y. Huang, Platinum nanoparticles using wood nanomaterials: eco-friendly synthesis, shape control and catalytic activity for $p$-nitrophenol reduction, Green Chem. 13 (2011) 283-287.

8. A. Saha, B. Ranu, Highly chemoselective reduction of aromatic nitro compounds by copper nanoparticles/ammonium formate,
J. Org. Chem. 73 (2008) 6867-6870.

9. Y.G. Wu, M. Wen, Q.S. Wu, H. Fang, $\mathrm{Ni} /$ graphene nanostructure and its electron-enhanced catalytic action for hydrogenation reaction of nitrophenol, J. Phys. Chem. C 118 (2014) 6307-6313.

10. R. Dey, N. Mukherjee, S. Ahammed, B.C. Ranu, Highly selective reduction of nitroarenes by iron (0) nanoparticles in water, Chem. Commun. 48 (2012) 79827984.

11. J. Han, L.Y. Li, R. Guo, Novel approach to controllable synthesis of gold nanoparticles supported on polyaniline nanofibers, Macromolecules 43 (2010) 10636-10644.

12. K.B. Narayanan, N. Sakthivel, Synthesis and characterization of nano-gold composite using Cylindrocladium floridanum and its heterogeneous catalysis in the degradation of 4nitrophenol, J. Hazard. Mater. 189 (2011) 519-525.

13. S.K. Das, C. Dickinson, F. Lafir, D.F. Brougham, E. Marsili, Synthesis, characterization and catalytic activity of gold nanoparticles biosynthesized with Rhizopus oryzae protein extract, Green Chem. 14 (2012) 1322-1334.

14. A. Gangula, R. Podila, M. Ramakrishna, L. Karanam, C. Janardhana, A.M. Rao,Catalytic reduction of 4-nitrophenol using biogenic gold and silver nanoparticles derived from Breynia rhamnoides, Langmuir 27 (2011) 1526815274.

15. K.B. Narayanan, N. Sakthivel, Biological synthesis of metal nanoparticles by microbes, Adv. Coll. Interface 156 (2010) $1-13$.

16. M. Franco-Romano, M.L.A. Gil, J.M. Palacios-Santander, J.J. Delgado-Jaén, I. Naranjo-Rodríguez, J.L. Hidalgo-Hidalgo de Cisneros, L.M. Cubillana-Aguilera, Sonosynthesis of gold nanoparticles from a geranium leaf extract, Ultrason. 
Sonochem. 21 (2014) 1570-1577.

17. L. Fairbrother, B. Etschmann, J. Brugger, J. Shapter, G. Southam, F. Reith, Biomineralization of gold in biofilms of Cupriavidus metallidurans, Environ. Sci. Technol. 47 (2013) 2628-2635.

18. A. Sugunan, P. Melin, J. Schnürer, J.G. Hilborn, J. Dutta, Nutrition-driven assembly of colloidal nanoparticles: growing fungi assemble gold nanoparticles as microwires, Adv. Mater. 19 (2007) 77-81.

19. P. Mohanpuria, N.K. Rana, S.K. Yadav, Biosynthesis of nanoparticles: technological concepts and future applications, J. Nanopart. Res. 10 (2008) 507-517.

20. G.S. Dhillon, S.K. Brar, S. Kaur, M. Verma, Green approach for nanoparticle biosynthesis by fungi: current trends and applications, Crit. Rev. Biotechnol. 32 (2012) 49-73.

21. A.R. Binupriya, M. Sathishkumar, K. Vijayaraghavan, S.I. Yun, Bioreduction of trivalent aurum to nano-crystalline gold particles by active and inactive cells and cell-free extract of Aspergillus oryzae var. viridis, J. Hazard. Mater. 177 (2010) 539-545.

22. A. Mishra, M. Kumari, S. Pandey, V. Chaudhry, K.C. Gupta, C.S. Nautiyal, Biocatalytic and antimicrobial activities of gold nanoparticles synthesized by Trichoderma sp, Bioresour. Technol. 166 (2014) 235-242.

23. T. Ahmad, I.A. Wani, N. Manzoor, J. Ahmed, A.M. Asiri, Biosynthesis, structural characterization and antimicrobial activity of gold and silver nanoparticles, Coll. Surface. B 107 (2013) 227-234.

24. A. Chauhan, S. Zubair, S. Tufail, M.A. Sherwani, M. Sajid, C.R. Suri, Fungusmediated biological synthesis of gold nanoparticles: potential in detection of liver cancer, Int. J. Nanomed. 6 (2011)
2305-2319.

25. N. Jain, A. Bhargava, S. Majumdar, J.C. Tarafdar, J. Panwar, Extracellular biosynthesis and characterization of silver nanoparticles using Aspergillus flavus NJP08: a mechanism perspective, Nanoscale 3 (2011) 635-641.

26. Y.Y. Qu, S.N. Shi, F. Ma, B. Yan, Decolorization of reactive dark blue KR by the synergism of fungus and bacterium using response surface methodology, Bioresour. Technol. 101 (2010) 80168023.

27. N. Vigneshwaran, N.M. Ashtaputre, P.V. Varadarajan, R.P. Nachane, K.M. Paralikar, R.H. Balasubramanya, Biological synthesis of silver nanoparticles using the fungus Aspergillus flavus, Mater. Lett. 61 (2007) 1413-1418.

28. V.C. Verma, R.N. Kharwar, A.C. Gange, Biosynthesis of antimicrobial silver nanoparticles by the endophytic fungus Aspergillus clavatus, Nanomedicine 5 (2010) 33-40.

29. M. Saravanan, A. Nanda, Extracellular synthesis of silver bionanoparticles from Aspergillus clavatus and its antimicrobial activity against MRSA and MRSE, Coll. Surface. B 77 (2010) 214-218.

30. K.C. Bhainsa, S.F. D'souza, Extracellular biosynthesis of silver nanoparticles using the fungus Aspergillus fumigatus, Coll. Surface. B 47 (2006) 160-164.

31. R. Bhambure, M. Bule, N. Shaligram, M. Kamat, R. Singhal, Extracellular biosynthesis of gold nanoparticles using Aspergillus niger-its characterization and stability, Chem. Eng. Technol. 32 (2009) 1036-1041.

32. R. Emmanuel, C. Karuppiah, S.M. Chen, S. Palanisamy, S. Padmavathy, P. Prakash, Green synthesis of gold nanoparticles for trace level detection of a hazardous pollutant (nitrobenzene) causing Methemoglobinaemia, J. Hazard. 
Mater. 279 (2014) 117-124.

33. P. Mukherjee, A. Ahmad, D. Mandal, S. Senapati, S.R. Sainkar, M.I. Khan, R. Ramani, R. Parischa, P.V. Ajayakumar, M. Alam, M. Sastry, R. Kumar, Bioreduction of $\mathrm{AuCl}_{4}{ }^{-}$ions by the fungus, Verticillium sp. and surface trapping of the gold nanoparticles formed, Angew. Chem. Int. Ed. 40 (2001) 35853588.

34. G. Singaravelu, J.S. Arockiamary, V.G. Kumar, K. Govindaraju, A novel extracellular synthesis of monodisperse gold nanoparticles using marine alga, Sargassum wightii Greville, Coll. Surface. B 57 (2007) 97-101.

35. N. Sharma, A.K. Pinnaka, M. Raje, A. FNU, M.S. Bhattacharyya, A.R. Choudhury, Exploitation of marine bacteria for production of gold nanoparticles, Microb. Cell Fact. 11 (2012) 1.

36. M.E. El-Naggar, T.I. Shaheen, M.M.G. Fouda, A.A. Hebeish, Eco-friendly microwave-assisted green and rapid synthesis of well-stabilized gold and coreshell silver-gold nanoparticles, Carbohydr. Polym. 136 (2016) 11281136.

37. K.B.A. Ahmed, D. Kalla, K.B. Uppuluri, V. Anbazhagan, Green synthesis of silver and gold nanoparticles employing levan a biopolymer from Acetobacter xylinum NCIM 2526, as a reducing agent and capping agent, Carbohydr. Polym. 112 (2014) 539-545.

38. M. Gajbhiye, J. Kesharwani, A. Ingle, A. Gade, M. Rai, Fungus-mediated synthesis of silver nanoparticles and their activity against pathogenic fungi in combination with fluconazole, Nanomed. Nanotechnol. Biol. Med. 5 (2009) 382-386.

39. S. Panigrahi, S. Basu, S. Praharaj, S. Pande, S. Jana, A. Pal, S.K. Ghosh, T. Pal, Synthesis and size-selective catalysis by supported gold nanoparticles: study on heterogeneous and homogeneous catalytic process, J. Phys. Chem. C 111 (2007) 4596-4605.

40. M. Rashid, T.K. Mandal, Templateless synthesis of polygonal gold nanoparticles: an unsupported and reusable catalyst with superior activity, Adv. Funct. Mater. 18 (2008) 2261-2271.

41. M.H. Rashid, R.R. Bhattacharjee, A. Kotal, T.K. Mandal, Synthesis of spongy gold nanocrystals with pronounced catalytic activities, Langmuir 22 (2006) 7141-7143.

42. K. Kuroda, T. Ishida, M. Haruta, Reduction of 4-nitrophenol to 4aminophenol over $\mathrm{Au}$ nanoparticles deposited on PMMA, J. Mol. Catal. A: Chem. 298 (2009) 7-11.

43. J. Li, C.Y. Liu, Y. Liu, Au/graphene hydrogel: synthesis, characterization and its use for catalytic reduction of 4nitrophenol, J. Mater. Chem. 22 (2012) 8426-8430.

44. P. Zhang, C.L. Shao, X.H. Li, M.Y. Zhang, X. Zhang, C.Y. Su, N. Lu, K.X. Wang, Y.C. Liu, An electron-rich freestanding carbon@Au core-shell nanofiber network as a highly active and recyclable catalyst for the reduction of 4nitrophenol, Phys. Chem. Chem. Phys. 15 (2013) 10453-10458.

45. X.D. Le, Z.P. Dong, W. Zhang, X.L. Li, J.T. Ma, Fibrous nano-silica containing immobilized $\mathrm{Ni@Au \quad core-shell}$ nanoparticles: a highly active and reusable catalyst for the reduction of 4nitrophenol and 2-nitroaniline, J. Mol. Catal. A Chem. 395 (2014) 58-65.

46. X.Q. Wu, X.W. Wu, Q. Huang, J.S. Shen, H.W. Zhang, In situ synthesized gold nanoparticles in hydrogels for catalytic reduction of nitroaromatic compounds, Appl. Surf. Sci. 331 (2015) 210-218.

47. Y.Y. Ju, X. Li, J. Feng, Y.H. Ma, J. Hu, X.G. Chen, One pot in situ growth of gold nanoparticles on amine-modified 
graphene oxide and their high catalytic properties, Appl. Surf. Sci. 316 (2014) 132-140.

48. C.N. Lok, C.M. Ho, R. Chen, Q.Y. He, W.Y. Yu, H. Sun, P.K.H. Tam, J.F. Chiu, C.M. Che, Proteomic analysis of the mode of antibacterial action of silver nanoparticles, J. Proteome Res. 5 (2006) 916-924.

49. N. Asmathunisha, K. Kathiresan, R. Anburaj, M.A. Nabeel, Synthesis of antimicrobial silver nanoparticles by callus and leaf extracts from saltmarsh plant, SesuviumportulacastrumL., Colloids Surf. B 79 (2) (2010) 488-493.

50. S. Gopal, H.G. Poosali, K. Dhanasegaran, P. Durai, D. Devadoss, R. Nagaiya, R. Balasubramanian, K. Arunagirinathan, V.S. Ganesan, Green synthesis of silver nanoparticles using Delphinium denudatum root extract exhibits antibacterial and mosquito larvicidal activities, Spectrochim. Acta Part A Mol. Biomol. Spectrosc. 127 (2014) 61-66.

51. S. Ghosh, S. Patil, M. Ahire, R. Kitture, S. Kale, K. Pardesi, S. S. Cameotra, J. Belleare, D.D. Dhavale, B.A. Chopade, Synthesis of silver nanoparticles using Dioscorea bulbifera tuber extract and evaluation of its synergistic potential in combination with antimicrobial agents, Int. J. Nanomed. 7 (2012) 483-496.

52. L. Kvitek, A. Panacek, J. Soukupova, M. Kolar, R. Vecerova, R. Prucek, M.
Holecova, R. Zboril, Effect of surfactants and polymers on stability and antibacterial activity of silver nanoparticles (NPs), J. Phys. Chem. C 112 (2008) 5825-5834.

53. P. Muthuraman, H.K. Doo,ZnO nanoparticles augment ALT, AST, ALP and $\mathrm{LDH}$ expressions in $\mathrm{C} 2 \mathrm{C} 12$ cells, Saudi J. Biol. Sci. 22 (6) (2015) 679-684.

54. Y. Matsumura, K. Yoshikata, S. Kunisaki, T. Tsuchido, Mode of bactericidal action of silver zeolite and its comparison with that of silver nitrate, Appl. Environ. Microbiol. 69 (2003) 4278-4281.

55. R.N. Kharwar, V.C. Verma, A.C. Gange, Biosynthesis of antimicrobial silver nanoparticle by endophytic fungus Aspergillus clavatus, Nanomedicine 5 (1) (2010) 33-40.

56. J.S. Kim, E. Kuk, K.N. Yu, J.H. Kim, S.J. Park, H.J. Lee, S.H. Kim, Y.K. Park, Y.H. Park, C.Y. Hwang, Y.K. Kim, Y.S. Lee, D.H. Jeong, M.H. Cho, Antimicrobial effects of silver nanoparticles, Nanomedicine 3 (2007) 95-101.

57. S. Ninganagouda, V. Rathod, H. Jyoti, D. Singh, K. Prema, U. H. Manzoor, Extracellular biosynthesis of silver nanoparticles using Aspergillus flavus and their antimicrobial activity against gram negative MDR strains, Int. J. Pharma Bio Sci. 4 (2) (2013) 222-229.

\section{How to cite this article:}

Alshehri, A.N.Z. 2019. Microbial Synthesis of Sliver Nanoparticles by Penicillium digitatum FCMR-728 and their Bionanocatalytic Reduction of 4-Nitrophenol and Antibacterial Activity. Int.J.Curr.Microbiol.App.Sci. 8(01): 2113-2126. doi: https://doi.org/10.20546/ijcmas.2019.801.221 